Cahiers $d u$ MONDE RUSSE

\section{Cahiers du monde russe}

Russie - Empire russe - Union soviétique et États indépendants

$53 / 4 \mid 2012$

Varia

\title{
Katerina Clark, Moscow, the Fourth Rome
}

\section{Gábor T. Rittersporn}

\section{OpenEdition \\ Journals}

Édition électronique

URL : http://journals.openedition.org/monderusse/7811

DOI : 10.4000/monderusse.7811

ISSN : $1777-5388$

Éditeur

Éditions de l'EHESS

Édition imprimée

Date de publication : 15 décembre 2012

ISSN : 1252-6576

\section{Référence électronique}

Gábor T. Rittersporn, «Katerina Clark, Moscow, the Fourth Rome », Cahiers du monde russe [En ligne], 53/4 | 2012, mis en ligne le 02 décembre 2013, Consulté le 25 septembre 2020. URL : http:// journals.openedition.org/monderusse/7811 ; DOI : https://doi.org/10.4000/monderusse.7811

Ce document a été généré automatiquement le 25 septembre 2020

(c) École des hautes études en sciences sociales 


\title{
Katerina Clark, Moscow, the Fourth Rome
}

\author{
Gábor T. Rittersporn
}

\section{RÉFÉRENCE}

Katerina CLARK, Moscow, the Fourth Rome. Stalinism, Cosmopolitanism, and the

Evolution of the Soviet Culture, 1931-1941. Harvard University Press : Cambridge, MA-London, 2011, 420 p.

1 De prime abord peu de choses relient la culture soviétique des années 1930 au phénomène du cosmopolitisme ou à la prophétie d'un obscur moine du Xvi siècle. Katerina Clark essaie de nous convaincre du contraire. Elle n'y parvient pas entièrement. Cependant, son livre est plein d'idées stimulantes. Il n'est pas d'une lecture facile mais il nous incite à chercher de nouvelles possibilités d'interpréter la culture et la société soviétiques des années 1930.

2 Aux alentours de 1524, le starets Filofej a déclaré dans une épître que deux Romes sont tombées, la troisième subsiste et il n'y en aura pas de quatrième. Il a fait allusion à la ville de Romulus, à Constantinople et à Moscou ainsi qu'à l'hégémonie hypothétique de cette dernière dans le monde chrétien et dans le monde tout court. Son oracle demeura peu connu jusqu'au XIX ${ }^{\mathrm{e}}$ siècle quand il fut vivement discuté. Mais il a intéressé peu de monde après la révolution et surtout pas les bolcheviks. Pourtant, on peut se demander si ceux-ci ne voulaient pas ériger la capitale soviétique en un digne successeur de la troisième Rome, sans qu'ils en soient conscients. Ce questionnement est l'un des fils conducteurs du livre. Malheureusement il disparaît souvent. À telle enseigne qu'on n'apprend pas à la fin de l'ouvrage ce qu'est devenue la quatrième Rome. On ne comprend pas non plus à quel point le projet fut imposé par les dirigeants du pays et dans quelle mesure il était celui de l'intelligentsia créatrice qui est au centre de l'ouvrage. 
3 La Moscou des bolcheviks était formée par la politique culturelle d'un État agressivement interventionniste. Habituellement, on souligne sa tendance à se refermer sur lui-même et à se défendre contre les influences étrangères. L'épilogue de l'étude montre que c'était le cas après la guerre. Mais le reste du livre apporte un grand nombre de preuves du dialogue entre la culture soviétique et le reste du monde au cours de la décennie d'avant-guerre. Selon Clark, les figures emblématiques de cette communication étaient des passeurs qu'elle désigne comme cosmopolites. Elle en a choisi quatre pour suivre leur va-et-vient entre le pays des Soviets et l'Occident ainsi que le destin des modèles culturels que ces passeurs transmettaient (on peut méditer sur la possibilité d'en trouver beaucoup d'autres). Il s'agit de Sergej Tret'jakov et de Sergej Eisenstein, dont les carrières de voyageurs étaient finies au début des années 1930, ainsi que d'Il'ja Erenburg et de son confrère Mihail Kol'tsov, qui ne cessèrent de vagabonder entre Moscou et l'océan Atlantique jusqu'à la veille de la guerre. D'une manière ou d'une autre tous les quatre voyageaient en serviteurs fidèles de l'État et de ce qu'ils prenaient pour la cause révolutionnaire.

À part les visiteurs occasionnels ou peu réguliers et quelques émigrés allemands que Clark évoque ponctuellement, elle ne parle guère d'intermédiaires étrangers. Il y en avait pourtant, par exemple, parmi les agents du Kominterm et des services de renseignement qui symbolisaient bien un certain internationalisme. Mais si ce dernier relevait de la médiation entre cultures, celles-ci étaient passablement éloignées de la littérature et des arts. Malgré tout, le rôle de Georgij Dimitrov, l'un des acteurs de l'éphémère rapprochement avec l'étranger au milieu des années 1930, reçoit la place qu'il mérite. Clark montre qu'à bien des égards Kol'cov aussi était un agent de Moscou pendant ses longs séjours en Espagne au cours de la Guerre civile. Mais il est sûr que la culture politique des Soviets qu'il tentait d'inculquer aux dirigeants et aux militants républicains n'avait rien à voir avec l'éclecticisme spontané d'un cosmopolitisme qui mérite ce nom. Aussi, comme Clark l'écrit, ses reportages et le livre qu'il en a tiré en 1938 étaient taillés à la mesure de la politique culturelle du temps des grandes purges. Il serait difficile d'y découvrir le détachement de l'homme du monde.

L'auteur prête une attention particulière à la question du cosmopolitisme et déploie une grande érudition pour le repérer dans l'histoire des civilisations modernes ainsi que dans l'œuvre des penseurs des Lumières. Mais elle est prudente quand il s'agit de caractériser celui de ses héros. Pour cause. Ils se sentaient à la maison un peu partout. Mais il manquait à leur habitus un élément essentiel du cosmopolitisme. Au lieu de s'attacher à des valeurs librement choisies, ils adhéraient avant tout à celles de la Russie bolchevique, telles qu'elles furent décrétées au gré des circonstances. Ceci a limité les milieux étrangers où ils évoluaient à ceux plus ou moins proches de l'URSS. Par surcroît, ce que Clark appelle le « cosmopolitisme patriotique » de ses protagonistes a laissé une forte empreinte sur leur approche de la culture qui fut bien sélective. Parfois ils voulaient influencer les choix de la politique culturelle et ils encaissaient quelques succès. Il n'en reste pas moins que leurs options étaient fonction de ce qu'ils croyaient compatible avec leur vision de leur patrie, même quand les idées qu'ils transmettaient testaient les limites de ce qu'ils comprenaient comme l'authenticité soviétique. Ce ne sont pas des valeurs per se qui les motivaient mais un projet social et politique qui s'y opposait à bien des égards. Ce projet était le programme implicite de la quatrième Rome et il a exclu nécessairement tout ce qui semblait le défier, même si 
c'était seulement les phantasmes de ses architectes qui ont suggéré l'imagerie de dangers.

6 À bien y regarder, dans le contexte soviétique le processus de médiation que Clark décrit consistait avant tout à l'importation de certains biens culturels et le refus de les accepter. Loin d'être cosmopolites, la plupart des importateurs étaient simplement des lettrés et des artistes plus ouverts au monde que le commun des intellectuels soviétiques. Les acrobaties théoriques de Georg (György) Lukács que l'auteur analyse astucieusement sont un excellent exemple de l'absence des vertus et des vices cosmopolites de la culture d'avant-guerre. Si les travaux du grand érudit hungarogermanique étaient débattus, les critiques et les défenseurs n'avaient rien à dire au sujet des origines étrangères de leurs fondements doctrinaux dont l'horizon international était trop restreint pour s'en apercevoir. De même, l'argument principal contre l'importation de telle ou telle autre influence était sa nature prétendument bourgeoise et non l'internationalisme fort éloigné de celui du prolétariat qu'elle pouvait véhiculer.

Clark explore essentiellement la littérature, la théorie littéraire, le théâtre et le cinéma. Elle consacre des pages brillantes à l'architecture mais les arts plastiques et la musique ne l'intéressent pas, à l'exception de la statue immense de Vera Muhina qui a coiffé le pavillon soviétique à l'Exposition internationale en 1937. Elle évoque en passant les titres de quelques tableaux exposés à la Foire internationale de New York en 1939. Mais seule la peinture d'Aleksandr Gerasimov représentant Stalin dans la compagnie de Gor 'kij, une œuvre qui a fait son chemin jusqu'à New York, mérite un coup d'œil pénétrant. C'est dommage car les discussions et les pratiques de création des peintres, des sculpteurs et des compositeurs nuanceraient les propos de l'auteur. Elles témoignent d'une hésitation entre genres et formes qui ne peuvent pas être réduits à des modèles soviétiques ou russes. Si bien que les influences étrangères sont inséparables des œuvres, même celles d'artistes qui n'ont jamais franchi les frontières et n'avaient aucune intention d'importer quoi que ce soit.

Ces problèmes et d'autres ne doivent pas masquer l'extraordinaire richesse du livre. Elle a tout pour désespérer le commentateur. Il est difficile de choisir un exemple qui montrerait tout l'éventail des références théoriques, historiques, littéraires et autres qui accompagnent les raisonnements audacieux de Clark. Mais essayons de prendre la statue de Muhina. L'auteur souligne les contrastes du piédestal monumental qui était le pavillon lui-même avec le projet pharaonique du Palais des Soviets, les deux ébauchés par Boris Iofan, ainsi que le dynamisme que suggèrent la construction de Paris et la sculpture. Elle les oppose au pavillon statique de l'Allemagne nazie qui faisait littéralement face à celui de l'URSS. La description ne serait pas tout à fait originale si elle ne conduisait pas à des réflexions sur les significations du dynamisme, du long drap flottant qui relie les figures autour des parties génitales, sur un tournant de la culture soviétique vers le romantisme, vers l'intime et vers le lyrisme (qu'un critique contemporain croyait voir dans les visages), sur la nouvelle importance qu'attribuaient les architectes à l'intérieur, sur un départ des grandes idées des Lumières et sur le masque au théâtre et dans les idées fixes des metteurs en scène des grands procès qui voulaient démasquer l'ennemi.

9 On est tenté d'élever des objections. Par exemple, l'idée d'un tournant marqué à la fin des années 1930 vers le romantique et vers l'intime est discutable, on peut arguer que le peu de choses de l'héritage des Lumières qui contribuait à façonner la culture russe a 
été vite gaspillé après la révolution et puisque Iofan était l'architecte principal du pavillon soviétique de New York, le bâtiment et la statue par Vjačeslav Andreev qui l'a couronné indiquent des continuités et des ruptures qu'il vaudrait la peine d'examiner. Peu importe. L'envergure des réflexions est saisissante. Elles ouvrent des perspectives insoupçonnées, par exemple quand Clark réfléchit à la tentation de l'aventure, de la passion, du danger, de la mort et de l'amour qui animait les engagés volontaires de la guerre d'Espagne, quand elle saisit les osmoses entre les œuvres étrangères sur le conflit et les conventions littéraires soviétiques ou quand elle parle de l'esthétique et $\mathrm{du}$ discours que devait incarner la quatrième Rome.

Il semble quelque peu osé de découvrir l'esprit des Lumières que l'auteur voit à l'œuvre dans les plans de reconstruire Moscou. Le plan du nouveau Berlin qu'elle ne peut pas contourner était plutôt inspiré par une réaction à cet esprit. Il est séduisant d'émettre l'hypothèse que la mégalomanie des rêves de l'urbanisme soviétique exprimait plus la démesure hallucinante de la tentative bolchevique de plier le monde à un projet qui échappait de plus en plus à ses auteurs que la détermination de matérialiser la raison. Il est dommage, du reste, que Clark n'essaie pas de chercher des parallèles entre le programme original de reconstruire Moscou qui ne sera pas mis en œuvre et la réalisation des projets d'urbanisme de Washington du début $d u x^{e}$ siècle qu'on a achevée dans les années 1930. Leur monumentalisme et leur recours aux moyens stylistiques du classicisme n'avaient rien à envier aux idéaux des constructeurs de la quatrième Rome. L'exploration de ces parallèles poserait des questions curieuses sur les liens entre les missions universelles et rédemptrices dont se réclamaient les pères fondateurs des États-Unis et les bâtisseurs de l'Union soviétique ainsi que sur la rationalité de leurs espoirs messianiques.

11 Souvent, la profusion d'idées, d'observations, d'associations et de références fait s'égarer l'auteur aussi bien que l'attention du lecteur. Ainsi, les longues pages que Clark consacre aux discussions sur les enseignements de l'opéra chinois par les hommes de théâtre, par les littérateurs et par les cinéastes en 1935 après la visite de la troupe de Mei Lanfang sont fascinantes. Mais les méandres de la narration, des flash-back et des pensées débordent largement le sujet du livre et mettent à l'épreuve ceux qui aimeraient suivre le fil des thèmes centraux. Il en va de même de la description minutieuse d'une multitude de théories qu'on peut résumer et dont on pourrait faire économie dans certains cas.

Parfois l'auteur veut relier trop de choses. Il est tentant d'écrire qu'en 1932 l'emblématique rue Gor'kij de Moscou débouchait sur l'avenue Marx qui n'a pourtant pas existé avant 1961. Il est habile de contraster l'humanisme de Wilhelm von Humboldt avec le bûcher de livres supposément anti-allemands que les nazis ont allumé en 1933 et dire que l'action a eu lieu devant l'université qui portait son nom, mais c'est oublier que la Friedrich-Wilhelms-Universität est devenue l'université Humboldt seulement en 1949. En 1934, la fameuse lettre de Stalin et de ses comparses sur deux projets de livres d'histoire a, certes, encouragé les comparaisons internationales mais les auteurs augustes n'ont pas soufflé mot sur les philosophes des Lumières que Clark aimerait y voir. Et que dire de l'alliance antifasciste qui aurait débuté en 1935 entre l'Union soviétique et le gouvernement du Front populaire en France et que la politique française vis-à-vis de l'Espagne républicaine n'aurait guère entamée? Serait-il mesquin d'égrener le long chapelet de ce genre d'erreurs et d'aller dans les détails de la présentation d'idées et de théories qui est parfois trop ajustée aux 
besoins du discours? Sans doute pas car il s'agit d'un livre fondé sur l'enchaînement d'éléments qui paraissent disparates mais qui sont censés se rapprocher dans des contextes et dans des conditions spécifiques.

13 Ajoutons tout de suite qu'il s'agit également d'un livre qui sert de leçon importante pour le chercheur. Le grand mérite de Katerina Clark est de l'encourager à aller plus loin que sa matière immédiate, à avoir le courage d'être à la quête des dimensions cachées de l'univers de son sujet, à prospecter dans les sources de prime abord étrangères à son thème et à laisser cours à son intuition sous la condition de peser tout ce qui risque d'ébranler ses hypothèses. Elle invite à oser défier les limites de ce que les autorités académiques prennent pour science, elle convie à l'aventure intellectuelle. 